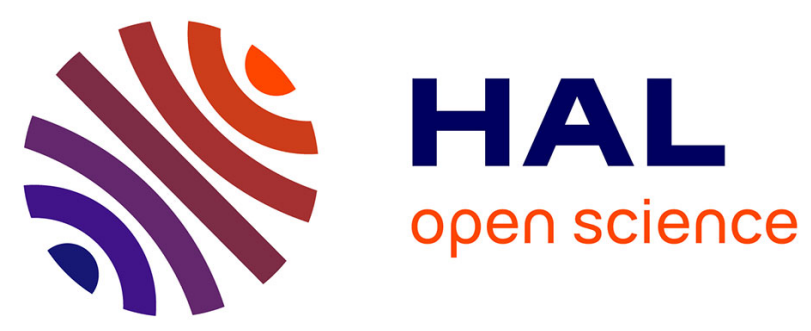

\title{
Quasi-Newton inversion of seismic first arrivals using source finite bandwidth assumption: Application to subsurface characterization of landslides
} Julien Gance, Gilles Grandjean, Kevin Samyn, Jean-Philippe Malet

\section{- To cite this version:}

Julien Gance, Gilles Grandjean, Kevin Samyn, Jean-Philippe Malet. Quasi-Newton inversion of seismic first arrivals using source finite bandwidth assumption: Application to subsurface characterization of landslides. Journal of Applied Geophysics, 2012, 87, pp.94-106. 10.1016/j.jappgeo.2012.09.008 . hal-00749309

\section{HAL Id: hal-00749309 \\ https://hal.science/hal-00749309}

Submitted on 7 Nov 2012

HAL is a multi-disciplinary open access archive for the deposit and dissemination of scientific research documents, whether they are published or not. The documents may come from teaching and research institutions in France or abroad, or from public or private research centers.
L'archive ouverte pluridisciplinaire HAL, est destinée au dépôt et à la diffusion de documents scientifiques de niveau recherche, publiés ou non, émanant des établissements d'enseignement et de recherche français ou étrangers, des laboratoires publics ou privés. 
1 Quasi-Newton inversion of seismic first arrivals using source finite

2 bandwidth assumption: application to landslides characterization 3 from velocity and attenuation fields.

4

5

Julien Gance (1,2), Gilles Grandjean(1), Kévin Samyn (1) and Jean-Philippe Malet (2)

(1) BRGM, Bureau de Recherches Géologiques et Minières, 3 Avenue Claude Guillemin, F-45060 Orléans, France

(2) Institut de Physique du Globe de Strasbourg, CNRS UM7516, EOST/Université de Strasbourg, 5 rue Descartes, 67084 Strasbourg Cedex, France.

Corresponding author:

Julien GANCE

BRGM, Natural Hazard Department.

3 Avenue Claude Guillemin BP36009 45060 Orléans Cedex 2, France

Phone : $+33(0) 238643819$

Fax : +33(0)2 38643549

E-mail address: j.gance@brgm.fr

Keywords:

Inverse theory, Seismic tomography, Fresnel wavepaths, Finite frequency, Resolution improvement, Landslide 


\section{Introduction}

Near-surface geophysical techniques are of great potential to image subsurface structures in many geomorphological studies (Schrottand Sass, 2008; van Dam, 2010), and even more specifically for improving the knowledge on landslide features (JongmansandGarambois, 2007). Landslide analysis generally involves the combined use of several geophysical methods to image different petrophysical parameters (Bruno andMarillier, 2000; Mauritsch et al., 2000; Méric et al., 2011). Seismic surveys are particularly well adapted to detect and characterize specific features of landslides such as spatial variation in compaction and rheology of the material (Grandjean et al., 2007), variation in fissure density at the surface (Grandjean et al., 2012), and complex slip surface geometries (Grandjean et al., 2006). As the wave propagation is mainly controlled by the elastic properties of the medium, seismic surveys are often well correlated with geotechnical observations.

Among them, different approaches can be used for processing data depending on the analysisof the different kind of waves associated to particular propagation phenomena. Bichler et al. (2004) and Bruno andMarillier (2000) interpreted the late arrivals of P-waves to image the bedrock geometry using seismic reflection analysis. Mauristch et al. (2000) and Glade et al. (2005) analyzed refracted waves to define the internal geometry (e.g. layering) of the landslides. Grandjean et al. (2007) and Grandjean et al. (2011) studied the first arrival traveltimes to recover P-wave velocity distribution across landslides. More recently, Samyn et al. (2011) used a 3D seismic refraction traveltime tomography to provide a valuable and continuous representation of the 3D structure and geology of a landslide. Grandjean et al. (2007) and Grandjean et al. (2011) used also Spectral Analysis of Surface Waves (SASW) techniques to obtain S-wave velocity distributions along landslide cross-sections. Finally, based on the work of Pratt (1999) and VirieuxandOperto (2009), Romdhane et al. (2011) demonstrated the possibility to exploit the entire wave signal by performing a Full elastic Waveform Inversion (FWI) on a dataset acquired on a clayey landslide.

These methods are based on more or less important assumptions on the soil type and their petrophysical characteristics, on the complexity of layers, and on their geometry, and are therefore not 
recommended for all case studies. Seismic refraction can be basically performed using the General Reciprocal Method (GRM; Palmer and Burke-Kenneth, 1980) or the Plus/Minus Method (Hagedoorn, 1959). These methods are fast and easy to implement, but mostly based on simple hypotheses - such as a layered media - and are consequently not very efficient to recover important variations in lateral velocity. Reflection surveys need to record high frequency waves to obtain a good resolution of final stacked sections; they are difficult to set up for subsurface applications because of the strong attenuation affecting high frequencies and decreasing the signal to noise ratio (Jongmansand Garambois, 2007). Moreover, this method produces a reflection image that cannot be directly and easily interpreted asdirect information on the mechanical properties of the medium that could be derived from velocity fields. FWI appears to be the more advanced method since it is based on the realistic assumption of an elastic media and uses the whole seismic signal in the inversion scheme. However, it remains a complex method, requiring an important data pre-processing (source inversion, amplitude correction, initial model estimation) that is hardly applicable to near surface real data featured with a low signal to noise ratio and complex waves interactions (Romdhane et al., 2011). As a consequence, the issue of recovering the structural image of a landslide from the seismic velocity field estimated with an accurate method is still a challenge.

The objective of this work is to refine the first arrival tomography approach applied to landslide analysis, which is a good compromise between the strong assumptions made in simple refraction methods and the complexity of the FWI approach when used in very heterogeneous soils. P-wave tomography is largely used, from crustal to shallow geotechnical studies and allows recovering, at a relatively low cost, a reliable image of the velocity distribution. In this perspective, Taillandier et al. (2009) proposed to invert first arrival traveltime tomography using the adjoint state method, but had to face the problem of gradient regularization. The proposed method is based on a Hessian formulation (Tarantola, 1987) to ensure an optimum convergence of the velocity model during iterations. We only use here the first arrivals of the seismic signal caused by direct or refracted waves. In that case, late arrival, including scattering, conversion effect are not taken into account in the inversion.

In the next section, we detail the theory used to formulate the inversion equation and the related approximations introduced for optimizing the algorithm and ensuring the convergence toward the best 
solution. The final algorithm is tested on a synthetic case in order to estimate the quality of the velocity field reconstruction without considering noisy data. To compare our results with a reference case, the synthetic velocity model is identical to the one used by Romdhane et al. (2011). Then, we process a real seismic dataset obtained from a seismic survey at the Super-Sauze landslide (South French Alps) in clayey material. On this case study, we invert for the P-wave velocity field but also for the attenuation factor. The effects of noisy data on the quality of the reconstructed velocity field are analyzed, and the observed surface variation in the velocity field is discussed by integrating other sources of information (geotechnical tests and geomorphological interpretation).

\section{Theoretical approach}

\section{a. General inverse problem}

Solving the inverse problem requires a modeling step (e.g. the direct problem) for computing the residuals (e.g. the difference between computed and observed data). An updated model can be estimated by back-projecting the data residuals on each cell of the model discrete grid. The direct problem thus consists in finding a relation between the data $t$, taken here as the first arrival traveltimes, and the physical P-wave velocity model $s$, such as:

$$
t=f(s)
$$

This problem is generally solved using the asymptotic high frequency wave propagation assumption in a non-homogeneous isotropic medium. The wave propagation equation is then simplified into the eikonal equation that computes the first arrival traveltimes over a discrete grid for example by using a finite-difference scheme (Vidale, 1998). This technique has been improved for sharp velocity contrasts (PodvinandLecomte, 1991), optimized by PopoviciandSethian (1998) who proposed the Fast Marching Method (FMM), by Zhao (2005) who proposed the Fast Sweeping Method, and recently adapted to non-uniform grids (Sun et al., 2011). The technique is actually largely used because of its efficiency and accuracy. In this study, we use the FMM algorithm 
(PopoviciandSethian, 1998) to compute the direct problem. The computation of the first arrival traveltime is generally followed by a ray tracing that uses the traveltimes maps to propagate the wavepath from the sources to the receivers. The traveltime $t$ can then be expressed using the following matrix form:

$$
t=L s
$$

where $\mathrm{L}$ is the length of the ray segment crossing each cell of the slowness model $S$. Generally, the Fermat principle allows the Fréchet derivatives matrix to be approximated by the matrix $L$ (Baina, 1998). This principle establishes that a small perturbation $\delta s$ on the initial model does not change the ray paths, and therefore, only affect the traveltime $\delta t$ at the second order. This linearization of the problem around the slowness model $s^{k}$ implements the Quasi-Newton $(\mathrm{Q}-\mathrm{N})$ assumption and makes the resolution of the nonlinear problem to be solved by the following tomographic linear system:

$$
\left[\left(L^{k}\right)^{T} L^{k}\right] \delta s=\left[\left(L^{k}\right)^{T} \delta t\right]
$$

where $\mathrm{k}$ and $\mathrm{T}$ represent respectively the iteration index and the transpose operator. Several techniques can be used to solve Eq. 3. The Simultaneous Iterative Reconstruction Technique (SIRT) is the most common because it does not require a large computer memory; consequently, SIRT is widely used to invert large sparse linear systems (Trampertand Leveque, 1990). Its convergence toward a least-square solution has been proved (Van der Sluisand Van der Vorst, 1987) but this method suffers from few drawbacks: SIRT introduces an intrinsic renormalization of the tomographic linear system that modifies slightly the final solution. For that reason, we propose to use in our approach the LSQR (Least-Square QR) algorithm (Paige and Saunders, 1982) that has been proved to be superior to SIRT or Algebraic Reconstruction Techniques ART algorithms in terms of numerical stability and convergence rates (Nolet, 1985).

\section{b. From rays to Fresnel volumes}


Revisiting seismic traveltimes tomography also needs to consider the ray approximation, e.g. the infinite spectral bandwidth assumption. The main issue of this approximation lies in the traveltime computation taken as line integrals along the rays spreading over the slowness model. Because the slowness values are only considered along ray paths, the problem is often underdetermined and leads to numerical instability (Baina, 1998). In practice, this difficulty is generally by-passed using regularization operators to reduce the non-constrained part of the model, and then, to reinforce the numerical stability. Generally, a simple smoothing of the reconstructed slowness model (Zeltand Barton, 1998), the application of a low-pass filter on the gradient (Taillandier, 2009) or the elimination of the lowest eigenvalues in the Hessian matrix (Tarantola, 1987) can be used. However, such regularization operators require the selection of appropriate parameters (filter length, eigenvalue cutoff and more generally the size and weights of the smoothing operators). Kissling et al. (2001) demonstrated the dependency of these parameters on the resolution and the quality of the final model in poor wavepath coverage areas. This is the reason why the use of physically-based regularization operators such as Fresnel volumes or sensitivity kernels is preferable since they are based on nonsubjective principles completely defined by the problem.

With this assumption, several methods have been developed including those using the concept of Fresnel volumes as a regularization factor. Nolet (1987) proposed to use the size of the Fresnel zone to constrain the size of a spatial smoothing operator. Vasco et al. (1995), Watanabe et al. (1999), Grandjean and Sage (2004) or Ceverny (2001) use the Fresnel volume in the back projection of the residuals.

More recently, the concept of sensitivity kernels or Fréchet Kernel introduced by Tarantola (1987) has been reformulated for traveltime tomography. It represents a good compromise between the strong assumption of the asymptotic ray theory and the high computational cost of the complete full wave inversion tomography (Liu et al., 2009). While ray theory is well adapted in media characterized by geological structures larger than the first Fresnel zone, the use of sensitivity kernels allows to overcome this constraint and then, to increase the spatial resolution (SpetzlerandSnierder, 2004). Several authors have developed this concept and investigated the properties of the sensitivity kernels for traveltime tomography in homogeneous media, mainly at the spatial scale of the earth crust 
(Dahlen et al., 2000; Dahlen, 2005; Zhao et al.; 2006). The strategies proposed by these authors are generally limited to smoothly heterogeneous media (Liu et al., 2009; Spetzler et al., 2008) and are barely applied to real datasets, mainly because of prohibitive calculation costs (Liu et al., 2009).

Sensitivity kernels and Fresnel volumes are constructed on the single scattering (Born) approximation. This approximation considers that a part of the wave can be delayed by velocity perturbation in the vicinity of the ray path. For highly heterogeneous media, this approximation is not valid anymore because multiple scattering should be taken into account to fully explain observed first arrivals.

In the particular case of subsurface soil investigation where highly heterogeneous media are observed, the use of sensitivity kernels is not recommended since it would involve complex algorithms and computing times similar to those featuring the FWI approach. In this context, we decided to solve empirically the problem of complex multiple scattering inside the first Fresnel zone, this approach allowing to address issues of regularization by using increasing finite frequencies bandwidths. Therefore, the developed algorithm assumes thathigh spatial heterogeneities of the soil around the Fresnel wavepath affect, through complex multiple scattering, the first arrivals of the signal.

In the next section, we explain how the Fresnel volumes are defined as a simplification of the sensitivity kernels and implemented in a Q-N algorithm.

We first express the Fresnel weights proposed by Watanabe et al. (1999) and used by Grandjean and Sage (2004), in order to materialize the wavepath in the model. They classically decrease linearly from a value of one (when the cell is positioned on the ray path) to a value of zero (when it is out of the Fresnel volume):

$$
\omega=\left\{\begin{array}{rrr}
1-2 f \Delta t, & 0 \leq \Delta t<\frac{1}{2 f} \\
0, & \frac{1}{2 f} \leq \Delta t
\end{array}\right.
$$



that a slowness perturbation delay the arrival of the wave by a $\Delta \mathrm{t}$, where $f$ is the considered frequency of the wave. This definition is interesting because of its simple expression that allows fast computing while taking into account the global shape of the 2D traveltime sensitivity kernel given of SpetzlerandSnieder (2004), corresponding to a decrease of sensitivity until the first Fresnel zone.

Because the size of the Fresnel volume is depending on the considered source frequency, a new inversion strategy based on increasing frequency can be proposed. To consider the entire source frequency content, some authors compute wavepaths in a band-limited sensitivity kernel, stacking the monochromatic kernels with a weight function similar to the amplitude spectrum of the wavelet (SpetzlerandSnieder, 2004; Liu et al., 2009). From our side, we propose to compute the Fresnel weights for a monochromatic wave, increasing its frequency at each step of the inversion. The considered frequency sampling with an increasing rule ranging from the lower to the higher frequency of the source signal. We also choose to give the same weight to all frequencies in order to limit the number of iteration and to preserve the rapid convergence of the algorithm. Taillandier et al. (2009) showed that this method, applied on the gradient filtering permit to overcome the non-linearity of the problem. For low frequency values, the Fresnel zone will be wider and the slowness model will be reconstructed with large wavelengths. Conversely, for high frequency values, the Fresnel zone will be thinnerand the slowness model will be reconstructed with sharp wavelengths. This strategy appears efficient to improve the resolution during the inversion - and so the convergence of the algorithm - in full wave inversion where it prevents from cycle-skipping issues (Sirgueand Pratt, 2004; VirieuxandOperto, 2009; Romdhane, 2011). Recovering slowness variations whose sizes are in agreement with each wavelength transmitted by the source should lead to better images of local heterogeneities while preserving the algorithm convergence.

With these assumptions, the traveltime perturbation can be expressed as the integral over a Fresnel volume multiplied by the slowness perturbation field observed for all points $r$ in the volume (Liu et al, 2009). This linear relationship among traveltime and slowness perturbation is the result of the first Born approximation that is only valid for small perturbation (Yomogida, 1992): 


$$
\delta t=\int W(r) \delta s(r) d r
$$

219 for each receiver such as for the cell $\mathrm{j}$ and for the couple source-receiver $\mathrm{i}$ : perpendicular to the raypath $a$, for each shot and receiver such as:

$$
W(r)=\frac{1}{a} \omega(r)
$$
sensitivity kernels:

$$
\int_{-\infty}^{+\infty} W(s, r, f) d s=1
$$
be written in its matrix form (Vasco et al, 1995):

$$
\delta t=W \delta s
$$

where $W$ is the Fresnel weight operator (Fig. 1) normalized by the area of the Fresnel ellipse

This normalization allows linking our approach to the geometrical ray theory in the case of a plane wave propagation (Vasco et al, 1995; Spetzler and Snieder, 2004; Liu et al, 2009), so that the integral of $\mathrm{W}$ over a surface perpendicular to the wavepath is equal to one, which is generally verified for

The Fresnel volume thus defined, also called Fréchet kernel corresponds to the Fréchet derivative (Yomogida, 1992; Tarantola, 1987) or Jacobian matrix of the forward problem, similar to the length of ray segment matrix $L$ defined in the asymptotic ray theory. The problem, considered in $2 \mathrm{D}$, can then

$$
W_{i j}=\frac{\omega_{i j}}{l}
$$


wherel is the length of the Fresnel surface along a direction perpendicular to the ray path.

We are however aware that the use of the Fresnel weight as defined previously is a rough approximation of the wavepath. This is the reason why we prefer to keep the ray assumption to compute traveltimes, avoiding the introduction of any error due to this approximation. Thischoice has been justified by Liu et al. (2009) who observed small differences between traveltime values computed with both approaches.

\section{c. New implementation of the inverse Problem}

In the previous section, we showed that the Born approximation combined with Fresnel volumes allowed the estimation of Fréchet derivative. To solve the nonlinear inverse problem, we use a steepest descent iterative algorithm to minimize the $L_{2}$ norm misfit function 1 (Tarantola, 1987) that can be written in this particular case:

$$
l(s)=\frac{1}{2}\left[\left(f(s)-t_{o b s}\right)^{T} C_{T}^{-1}\left(f(s)-t_{o b s}\right)+\left(s-s_{\text {prior }}\right)^{T} C_{S}^{-1}\left(s-s_{\text {prior }}\right)\right]
$$

where $C_{T}$ and $C_{S}$ are respectively the covariance operators on data and model, $f$ represents the theoretical relationship between the model $s$ and the traveltimes $t, t_{o b s}$ the observed data and $s_{\text {prior }}$ the a priori information on the model.

The Q-N method consists in minimizing the misfit function iteratively using its gradient and approximated Hessian matrix. The gradient gives the direction of steepest descent of the misfit function while the Hessian matrix is used as a metric indicating its curvature, approximated locally by a paraboloïd (Tarantola, 1987). Compared to the gradient method, the Hessian is here used to improve the assessment of direction and norm of the update vector that is applied to the slowness model, so that each step is performed in the good direction and with an optimized length. The tomographic linear system in the case of no a priori information on the model can be written in its matrix form: 


$$
\left[\left(W^{k}\right)^{T} C_{T}^{-1}\left(W^{k}\right)\right] \delta s=\left[\left(W^{k}\right)^{T} \delta t\right]
$$

This linear tomographic system can be solved by using a LSQR algorithm. The Fresnel weights matrix employed is a [number of data $x$ number of cells] matrix. Its computation is straightforward on classical personal computers. The Q-N algorithm is based on the inverse of the Hessian matrix that is a square matrix of size [number of data x number of data] that can be difficult to invertfor large dataset. In our case, we used cluster computing to invert our data and optimized the step size along the direction given by the Hessian using a scalar to weight the slowness update thanks to a parabolic interpolation (Tarantola, 1987).

\section{d. Validation on a synthetic dataset}

To compare the performance of our algorithm with full wave inversion, it was tested on the synthetic transverse section used by Romdhane (2011) representing a typical cross-section of a landslide (Fig. 2a). The performance of the method is discussed by taking as a reference the SIRT algorithm of Grandjean and Sage (2004).

The synthetic dataset has been calculated with a simple 2D eikonal equation solver, so that traveltimes are not perturbed by scattering effects. The dataset is composed of 50 shots recorded on 100 geophones. The model consists in 209x68 cells of $1 \mathrm{~m}$ in width. The seismic sources are spaced regularly every $2 \mathrm{~m}$ and the geophones every $1 \mathrm{~m}$. The synthetic model is composed of ten layers with P-wave velocity ranging from $110 \mathrm{~m} \cdot \mathrm{s}^{-1}$ to $3300 \mathrm{~m} . \mathrm{s}^{-1}$. It represents a transversal cross-section of the landslide body lying on a homogeneous consolidated bedrock. Except between the landslide body and the bedrock, the changes in P-wave velocity are small, so that it is difficult to reconstruct the detailed shape of the landslide body. The stopping criterion is a change in the cost function lower than $1 \%$ and the inversion is limited to 20 steps.

Figure $2 \mathrm{~b}$ and $2 \mathrm{c}$ compare the results obtained with the SIRT algorithm (Grandjean and Sage, 2004) and the Q-N one. They converge respectively in 15 and 20 iterations. The convergence of the misfit function is better for the Q-N algorithm with a value 3.6 times lower than the SIRT. Globally, the Q-N 
algorithm succeeds in recovering the shape of the bump at $2000 \mathrm{~m} \cdot \mathrm{s}^{-1}$ located on the left side of the cross-section and renders a more spatially detailed shape of the bedrock topography (Fig. 2b, 2c). The SIRT algorithm does not retrieve those initial structures. We can notice that both algorithms have difficulties to reproduce the low velocity of the very near surface layer, because of the poor ray coverage occurring in this area.

Figure $2 \mathrm{~d}, 2 \mathrm{e}$ and $2 \mathrm{f}$ compare the results on three vertical cross-sections chosen to highlight the ability of the algorithm to recover P-wave velocity with a better accuracy than the SIRT. We can notice that for the top-soil, P-wave velocity are the same for both algorithms and are equal to the P-wave velocities of the initial model in that zone. Moreover, The Q-N algorithm seems to be able to recover lowest wavelengths than the SIRT one as on figure $2 \mathrm{~d}$ between 55 and $60 \mathrm{~m}$ of depth.

This synthetic example demonstrates the ability of the Q-N algorithm to recover the shape of the internal layers of a landslide body. Contrary to the SIRT result, the Q-N allows to interpret correctly the thickness and geometry of the different layers.

\section{Application of the $\mathrm{Q}-\mathrm{N}$ algorithm on a real dataset}

\section{a. Study site presentation}

The Q-N algorithm has been applied on a real dataset acquired at the Super-Sauze landslide (South French Alps). The landslide has developed in Callovo-Oxfordian black marls. Its elevation is between $2105 \mathrm{~m}$ at the crown which is established in in-situ black marls covered by moraine deposits and 1740 $\mathrm{m}$ at the toe. The landslide is continuously active with displacement rates of 0.05 to $0.20 \mathrm{~m}^{\mathrm{day}}{ }^{-1}$ (Malet et al., 2005a). The detachment of large blocks of marls from the main scarp (Fig. 3) and their progressive mechanical and chemical weathering in fine particles explain the strong grain size variability of the material especially in the topsoil (e.g. decametric blocks of marls at various stages of weathering, decimetric and centimetricclasts of marls, silty-clayed matrix; Maquaire et al., 2003). The bedrock geometry is complex with the presence, in depth, of a series of in-situ black marl crests and gullies, partially or totally filled with the landslide material (Flageollet et al., 2000; Travelletti and Malet, 2012). This complex bedrock geometry delimits sliding compartments of different 
hydrogeological, rheological and kinematical pathways. The variable displacement rates and the bedrock geometry also control the presence of large fissures at the surface (Fig. 3b, 3c) that can be imaged with joint electrical and electromagnetic methods (Schmutz et al., 2000). Many kinds of heterogeneities are observed at different scales, and they control directly the mechanical behavior of the landslide by creating excess pore water pressures (Van Asch et al., 2006; Travelletti and Malet, 2012). The top soil surface characteristics have also a large influence on the surface hydraulic conductivity (Malet et al., 2003) and therefore, on the water infiltration processes (Malet et al., 2005b;Debieche et al., 2009). In this context, we tested the Q-N P-wave tomography inversion scheme to provide a high-resolution characterization of structures and detect small scale heterogeneities along aN-S transect of the landslide.

\section{b. P-wave velocities inversion}

The seismic profile is parallel to the main sliding direction of the material, and is located in the upper part from the secondary scarp to the middle part of the accumulation zone (Fig. 3). The base seismic device has a length of $94 \mathrm{~m}$ long and consisted of 48 vertical geophones (with a central frequency of 10 $\mathrm{Hz}$ ) regularly spaced every $2 \mathrm{~m}$. The 60 shots have been achieved with a hammer every $4 \mathrm{~m}$. We used a roll-along system to translate the acquisition cables with a 24 geophones overlap and then investigate a $238 \mathrm{~m}$ long linear profile. The recording length is $1.5 \mathrm{~s}$ with a sample rate of $0.25 \mathrm{~ms}$ and the acquisition central consists in a Geometrics Stratavizor seismic camera (48 channels). The shots show a relatively good signal to noise ratio until the last geophone in the upper part of the section. The shots of the lower part are affected by the higher density of soil fissures. The attenuation and the signal to noise ration are consequently higher in this part of the profile. The signal is dominated by the surface waves but the first arrivals are clearly visible for all seismic shots. 
345 To estimate the pick uncertainty, the timedifference of the picks from reciprocal source-receiver pairs

346 was examined. Two different people picked the first arrival of the waves, and for each created dataset

347 we studied the difference between reciprocal traveltimes. From each dataset, we created 3 subsets: a

348 first one kept intact, a second one where we corrected the picks having more than $10 \mathrm{~ms}$ of difference

349 in traveltime reciprocity, the picks being removed when not possible and a third one removing picks

350

351

352 having a difference of traveltime reciprocity greater than $10 \mathrm{~ms}$. We inverted the 6 datasets and kept the one which gave the lower final misfit function value and the P-wave tomogram the most reliable with our a priori knowledge of the studied zone. The differences between P-wave tomograms were not so important, but the dataset selected permitted to interpret the results unequivocally. The error in reciprocity of traveltimes can be approximated by a Gaussian belt with a standard deviation of $2.2 \mathrm{~ms}$ (Fig. 5).

The inversion has been performed with the Q-N algorithm on a 358 x 153 grid. Each square cell of the grid measures $0.67 \mathrm{~m}$. The hammer source gave frequencies comprised between $30 \mathrm{~Hz}$ and $120 \mathrm{~Hz}$ with a dominant frequency of $40 \mathrm{~Hz}$. Those frequencies are also present in the P-wave up to the end of the profile (Fig. 4b). Regarding the different amplitude spectra, we considered those values as constant for each shot. For the first iteration, the frequency was set to $30 \mathrm{~Hz}$ and then increases at each step to respectively $45 \mathrm{~Hz}, 60 \mathrm{~Hz}, 75 \mathrm{~Hz}, 90 \mathrm{~Hz}, 105 \mathrm{~Hz}$ and $120 \mathrm{~Hz}$; after the eighth steps, the frequency was kept constant at $120 \mathrm{~Hz}$.

The initial model is of a first importance for a good convergence. Indeed, the linearization of the problem around the initial model is only valid for model close to the real one. This reason motivates the automated calculation of the initial model from the data by using a simplified slant-stack algorithm transforming the dataset in the velocity - intercept times domain. Then, theoretical traveltime curves were calculated in a double loop for a velocity $\mathrm{v}$ rangingfrom $v_{\min }$ to $v_{\max }$ (defined by the user) and for a range of intercepts $\tau$ such as: 


$$
t=\tau+\frac{o f f \text { set }}{v}
$$

373

For each of these theoretical curves, the model was compared to the observed traveltimes; the number of points with a difference of less than $0.5 \mathrm{~ms}$ was stored in the $\tau$-p plan (Fig. 6a). For each intercept, the velocity corresponding to the maximum number of point was used to create a profile of velocity that is further used under the shot point (Fig. 6b).

The depth $d$ corresponding to each velocity was then deduced from the velocities by using Eq. 13:

$$
d(i)=d(i-1)+v(i) * \delta t
$$

where $\delta t$ represents the sample rate of intercepts (Fig. 6c).

The velocity profiles were gathered to form the initial model that was finally smoothed to avoid lateral artifacts. With a misfit function value of 0.3612 , this initial model is supposed to be as much as possible close to the final one which is the best way to avoid divergence or convergence in local minimum. The stopping criterion was set to a percentage change lower than $1 \%$ and the number of iteration was limited to 20 . The misfit function value associated to the final model is 0.0122 and has been obtained after 17 iterations.Figure 7 shows the misfit functions related to the Q-N and SIRT algorithms for comparison.

Figure 8 shows respectively the initial velocity model and the inverse models obtained with both SIRT and Q-N algorithms.

\section{c. Seismic wave attenuation tomography}

The amplitude of the first arrival is exploited here to image the wave attenuation. Seismic wave attenuation is an efficient physical property because it is directly linked to porosity and to the presence of fissures in the media (Schön, 1976). Several attenuation parameters can be used to invert seismic attenuation: spectral ratio, centroid frequency shift and peak frequency shift (De Castro Nunes et al., 
2011). In our analysis, we used the simple method proposed by Watanabe andSassa (1996)

considering that in a homogeneous attenuation media the amplitude of the spherical wave verifies:

$$
A(r)=\frac{A_{0}}{r} e^{-\alpha r}
$$

400

401

402

403

404

405

406

407

408

409

410

411

412

413

414

415

where $A_{0}$ is the amplitude of the source signal, $r$ the distance from the seismic source along the raypath and $\alpha$ the attenuation coefficient.

Applying a logarithm function, the equation becomes linear in $\alpha$. We proposed to compute the attenuation tomography after the P-wave velocity field so that the problem is reduced to a simple linear problem:

$$
\alpha=\alpha+W^{T} \delta A
$$

where $\alpha$ is the attenuation coefficient, $\delta A$, the amplitude update and $W$ the Fresnel weights matrix. We performed five iterations starting from a simple homogeneous media with an attenuation $\alpha=$ $1.0 e^{-03} \mathrm{~Np} \cdot \mathrm{m}^{-1}$ and calculated the Fresnel weights matrix for the Q-N inverted Vp model and for five frequencies $(30 \mathrm{~Hz}, 45 \mathrm{~Hz}, 60 \mathrm{~Hz}, 90 \mathrm{~Hz}, 120 \mathrm{~Hz})$. Although the results are generally presented through the dimensionless quality factor, in our case, the dominant source frequency is almost constant for each shot $(40 \mathrm{~Hz})$ and the raw results are more contrasted. Moreover, because the definition of the quality factor can be different for lossy (highly attenuating) materials (Schön, 1976), we image directly the attenuation map. In order to compare the attenuation map with surface fissuring, a geomorphological inventory of the fissures was created by direct observations in the field along the seismic profile. All the fissures of width larger than $0.05 \mathrm{~m}$ were mapped. The Surface Cracking Index (SCI), defined as the total length of fissures per linear meter of the seismic profile, is represented in Figure 9a.

\section{Interpretation and discussion}


The velocity model is firstly compared to the geometrical model proposed by Travelletti and Malet (2012) proposed from the integration of multi-source data (e.g. electrical resistivity tomographies, dynamic penetration tests and geomorphological observations) at coarser scale.

The bedrock depths obtained from penetration tests were used to deduce the minimum velocity of the bedrock fixed at $850 \mathrm{~m} \cdot \mathrm{s}^{-1}$. The bedrock position thus obtained is compared to the one of Travelletti and Malet (2012) along the profile (Fig. 10a, b). The thickness was calculated for both models with the topography observed in 2011. The depth interval observed is the same (2 to $13 \mathrm{~m}$ ) and the global shape of the bedrock is identical. The main differences are lower than $4 \mathrm{~m}$ and are located downhill of the profile, from the abscissa 100 to $230 \mathrm{~m}$ where the bedrock topography is more complex. It shows important high frequencies variations that are less pronounced on the topography from Travelletti and Malet (2012).

To assess the quality of the Q-N algorithm result, we compare the bedrock depth variation with the topography visible on a black and white orthophotograph of 1956 before the landslide (e.g. when the original relief was not covered by the landslide material). The figure 11a shows the orthophotograph of 1956 overlaid on the digital elevation model available for the same date. The seismic profile is also represented. We can notice on the picture the very irregular geometry of the relief composed of alternating crests and gullies of different sizes. The studied profile crosses different geometries. From the point A to B (Fig. 11a), the topography seems first regular, before crossing a large thalweg. After crossing this thalweg, the profile goes across a long transversal crest that forms a bump and then, plunges along the downstream slope. Those patterns are also present in the P-wave tomogram, respectively at $125,140 \mathrm{~m}$ and $160 \mathrm{~m}$.

Near the abscissa $180 \mathrm{~m}$, a zone of low velocities $\left(<900 \mathrm{~m} \cdot \mathrm{s}^{-1}\right)$ is observed in depth that can be interpreted as an old small-sized gully, also visible as a black dot on the orthophotograph.

From this observation, we constructed an interpreted geological model that gathers geophysical and geomorphological information (Fig. 11b). This model is composed of three different materials. The first one is the Callovo-Oxfordian intact black marls that constitute the bedrock, characterized by 
velocities greater than $3000 \mathrm{~m} . \mathrm{s}^{-1}$ (Grandjean et al., 2007) and with a topography following the one visible on the DEM from 1956. The second one is the unconsolidated material that presents P-wave velocities between 400 and $1200 \mathrm{~m} . \mathrm{s}^{-1}$, characteristic of unconsolidated deposits (Bell, 2009). It constitutes the active unit of the landslide, e.g. the layer that presents most displacements. The third material, characterized by an interval of velocities between 1500 and $2500 \mathrm{~m} \cdot \mathrm{s}^{-1}$ is interpreted as compacted landslide material, because it is only present at a higher depth, where the height of soil above is sufficient to compact the landslide deposit. This layer is not involved in the dynamics of the landslide andis quasi-impermeable (Malet, 2003; Flageollet et al., 2000; Travelletti and Malet, 2012).

Now that we proved the reliability of the Q-N algorithm tomography to recover the paleotopography, we can assess its contribution by comparing this result from the SIRT tomography of Grandjean and Sage (2004). We can notice on figure $8 \mathrm{~b}$ and $8 \mathrm{c}$, that the upper part of the profile (between the abscissa 0 and $100 \mathrm{~m}$ ) presents a smoother contrast between the active unit and the bedrock for the SIRT result. Although two bumps are visible at the abscissa 100 and $140 \mathrm{~m}$, the large in-between depression is not visible. In the lower part, the active layer is deeper than for the Q-N algorithm tomography and presents little lateral heterogeneity that prevent the interpreter from delimitating the landslide layer with accuracy. Globally, the SIRT tomography and the Q-N one are in agreement, but SIRT algorithm does not permit to recover the geotechnical unit limits with the same accuracy and prevents from distinguishing the "Dead body" represented in figure $11 \mathrm{~b}$.

To summarize, we proved that the Q-N algorithm previously developed presented a better horizontal and vertical resolution than the SIRT algorithm (Grandjean and Sage, 2004) and gives the possibility to interpret the bedrock geometry as geomorphological and geological patterns with more details and better resolution than previously. Thanks to the algorithm, we were able to clearly distinguish three of the four geotechnical units proposed by Flageollet et al. (2000). The active unit composed of C1a and C1b geotechnical layers, the "dead body" that represents the $\mathrm{C} 2$ layer and the bedrock. 
The seismic attenuation field obtained is in agreement with the P-wave velocities inversed. Although

479

480

481

482

483

484

485

486

487

488

489

490

491

492

493

494

495

496

497

498

499

500

501

502

503

P-wave velocity and seismic attenuation are not linked during the inversion, the attenuation field also permits to distinguish to main materials. The first one presents a relatively low attenuation, that correspond to the bedrock and the "dead body" gathered. The values obtained for this material are around $10^{-3} \mathrm{~Np} . \mathrm{m}^{-1}$, which corresponds to consolidated soils attenuation at $40 \mathrm{~Hz}$ (Schön, 1976). The second one is a more attenuating and heterogeneous material that corresponds to the landslide deposit. The attenuation of the landslide layer varies from 4 to $1210^{-3} \mathrm{~Np} \cdot \mathrm{m}^{-1}$ which are more typical values for unconsolidated soils at this frequency (Schön, 1976). The lateral heterogeneity of the attenuation is important. Areas of high attenuation show attenuation values three times higher than others. The correlation between the SCI and the attenuation is very good, so that we can affirm that attenuation variations are mainly caused by cracking.

The seismic wave attenuation tomography highlights two important attenuation zones. The first one, in the upper-part at the abscissas 20-30 seems to be concentrated at the interface between the landslide layer and the bedrock (Fig. 11b). In this area the landslide material undergoes significant shear stresses due to friction between the landslide layer and the bedrock topography. At the surface, cracks wider than $15 \mathrm{~cm}$ and measuring several meters in length are visible and the soil is completely remolded.The second zone seems to be associated to the influence of the local bedrock geometry that forms a bump followed by a steep slope (Fig. 11b). Its concave shape is responsible of the tension cracks well visible at the surface and clearly perpendicular to the major change of topography direction (Fig. 3c). Moreover, the soil seems dryer in that zone, certainly because of the geometry of the area that facilitates the drainage of the groundwater table toward lower areas. This phenomenon can even intensify the presence of cracks.

We can notice that P-wave velocity and seismic wave attenuation produce complementary results. Only the P-wave velocity tomography can reproduce the sharp geometry of the bedrock topography and differentiate the "dead body" from the bedrock (Fig. 11b). On the other hand, the seismic wave attenuation provides more information on the landslide layer lateral heterogeneity. 
Here, we can notice that the two high attenuation zones are not correlatedwith low P-wave velocity as expected (Grandjean et al., 2011). This is explained by the seismic wavepaths going through this weathered material, that are probably too short to impact the velocity, so that only scattering and diffusion effects affect the wave amplitudes.

Those complementary results highlight the importance of seismic attenuation tomography when characterizing weathering state of soils in near surface application.

It is finally important to note that this geophysical method is, in theory, not adapted to image the near surface zone (first meters in depth). Indeed, the poor Fresnel weighs coverage in that zone prevents to obtain high accuracy results. Moreover, cracks and attenuating objects size is certainly comparable or smaller than the cell size $(0.67 \mathrm{~m})$. So, we have to be cautious when interpreting those results because the real attenuation zones could be closer to the surface than those presented on the seismic attenuation tomography.

\section{Conclusions}

We present a P-wave tomography inversion algorithm for highly heterogeneous media which combine improvement of resolution and inversion regularization. We use the Fresnel wavepaths calculated for different sources frequencies to retropropagate the traveltime residuals, assuming that in highly heterogeneous media, the first arrivals are affected by velocity anomalies present in the first Fresnel zone through complex multiple scattering. After verifying the ability of the algorithm to recover complex structures on a synthetic dataset, we apply it on a real dataset acquired on the upper part of the Super-Sauze landslide. We verify that our results are in accordance with previous results from Travelletti and Malet (2012) and dynamics penetrometer tests. It appears that the sharp geometry of the bedrock topography is well recovered. This result is of first importance because bedrock topography is one of the main controlling factors of landslide displacement. Using the wavepaths calculated for P-wave velocity tomography inversion, we invert separately the seismic wave attenuation of the same dataset. Although barely applied in landslide environment, we show that with 
few efforts it was possible to use the amplitude of the first peak of the wave to get an accurate image of the seismic wave attenuation of the landslide layer. The results are in agreement with the observed surface crack inventory and bring complementary information for the construction of an interpreted model. The use of traveltimes and amplitude of waves permit to create an interpreted geological model that gathers those different details.

Such geological models are generally created for hazard assessment through numerical modeling. For this work, the use of geophysical tomography is essential because it is the only tool that can provide continuous and integrated imaging of the soil. In this perspective, our algorithm contribution is to answer one of the major issues raised by Travelletti and Malet(2012), namely, the lack of resolution of geophysical tomography compared to geotechnical tests and geomorphological observations.

This is why we believe that the Q-N algorithm could really improve the resolution of the geological model, and thus any numerical hydro-mechanical modeling using this variable as a parameter.

This work was supported by the French National Research Agency (ANR) within the Project SISCA "'SystèmeIntégré de Surveillance de Crises de glissements de terrains Argileux, 2009-2012" and the BRGM Carnot institute.

\section{References}

Baina, R.M.H. 1998. Tomographie sismique entre puits : mise en œuvre et rôle de l'analyse à posteriori vers une prise en compte de la bande passante. Phd Thesis.Université Rennes 1, France.

Bell, F.G. 2009.Engineering Geology.Second Edition. Elsevier, Oxford. 581p. 
Bichler, A., Bobrowsky, P., Best, M., Douma, M., Hunter, J., Calvert, T. and Burns, R. 2004. Threedimensional mapping of a landslide using a multi-geophysical approach: the Quesnel Forks landslide. Landslides, 1(1), 29-40.

Bruno, F. andMarillier, F. 2000. Test of high-resolution seismic reflection and other geophysical techniques on the Boup landslide in the Swiss Alps. Surveys in Geophysics, 21, 333-348.

Ceverny, V. 2001.Seismic ray theory. Cambridge University Press, Cambridge, 713p.

Dahlen, F.A., Hung, S.H. andNolet, G. 2000. Fréchet kernels for finite-frequency traveltimes-I. Theory.Geophysical Journal International, 141, 157-174.

Dahlen, F.A. 2005. Finite-frequency sensitivity kernels for boundary topography perturbations: Geophysical Journal International, 162, 525-540.

De Castro Nunes, B.I., de Medeiros, W.E., do Nascimento, A.F. and de Morais Moreira, J.A. 2011. Estimating quality factor from surface seismic data: a comparison of current approaches.Journal of Applied Geophysics, 75, 161-170.

Debieche, T.-H., Marc, V., Emblanch, C., Cognard-Plancq, A.-L., Garel, E., Bogaard, T.A. and Malet, J.-P. 2009. Local scale groundwater modelling in a landslide. The case of the Super-Sauze mudslide (Alpes-de-Haute-Provence, France). In: Malet, J.-P., Remaître, A. andBoogard, T.A. (Eds): Proceedings of the International Conference on Landslide Processes: from geomorphologic mapping to dynamic modelling, Strasbourg, CERG Editions, 101-106.

Flageollet, J.-C., Malet, J.-P. andMaquaire, O. 2000. The 3D Structure of the Super-Sauze Earthflow: A first stage towards Modelling its Behavior. Physics and Chemistry of the Earth, 25, 785-791.

Glade, T., Stark, P. andDikau, R. 2005.Determination of potential landslide shear plane depth using seismic refraction. A case study in Rheinhessen, Germany.Bulletin of Engineering Geology and the Environment, 64, 151-158.

Grandjean, G. and Sage, S. 2004. JaTS: a fully portable seismic tomography software based on Fresnel wavepaths and a probabilistic reconstruction approach. Computers and Geosciences, 30, 925-935.

Grandjean, G., Pennetier, C., Bitri, A., Meric, O. and Malet, J.-P. 2006. Caractérisation de la structure interne et de l'état hydrique de glissements argilo-marneux par tomographie géophysique 

:l'exemple du glissement-coulée de Super-Sauze (Alpes du Sud, France). Comptes Rendus Geosciences, 338, 587-595.

Grandjean, G., Malet, J.-P., Bitri, A. andMéric, O. 2007.Geophysical data fusion by fuzzy logic for imaging the mechanical behavior of mudslides.Bulletin Société Géologique de France, 177(2), 127136.

Grandjean, G., Gourry, J.-C., Sanchez, O., Bitri, A. andGarambois, S. 2011. Structural study of the Ballandaz landslide (French Alps) using geophysical imagery.Journal of Applied Geophysics, 75, $531-542$.

Grandjean, G., Bitri, A. andKrzeminska, M. 2012. Characterization of a landslide fissure pattern by integrating seismic azimuth tomography and geotechnical testing.Hydrological Processes.(in press).

Hagedoorn, J.G.1959., The plus-minus method of interpreting seismic refraction sections. Geophysical Prospecting, 7(2), 158-182.

Jongmans, D. andGarambois, S. 2007. Geophysical investigation of landslides: a review. Bulletin SociétéGéologique de France, 178(2), 101-112.

Kissling, E., Husen, S. andHaslinger, F. 2001.Model parameterization in seismic tomography: a choice of consequence for the solution quality. Physics of the Earth and Planetary Interiors, 123, 89-101.

Liu, Y., Dong, L., Wang, Y., Zhu J. and Ma, Z. 2009. Sensitivity kernels for seismic Fresnel volume tomography.Geophysics, 74, U35-U46.

Malet, J.-P., Auzet, A.-V., Maquaire, O., Ambroise, B., Descroix, L., Estèves, M., Vandervaere, J.-P. andTruchet E. 2003. Soil surface characteristics influence on infiltration in black marls: application to the Super-Sauze earthflow (Southern Alps, France). Earth Surface Processes and Landforms, 28, $547-564$.

Malet, J.-P., Laigle, D., Remaître, A. andMaquaire, O. 2005a.Triggering conditions and mobility of debris-flows associated to complex earthflows. Geomorphology, 66(1-4): 215-235.

Malet, J.-P., van Asch, Th.W.J., Van Beek, L.P.H. andMaquaire O. 2005b. Forecasting the behaviour of complex landslides with a spatially distributed hydrological model.Natural Hazards and Earth System Sciences, 5, 71-85. 
Maquaire, O., Malet, J.-P., Remaître, A., Locat, J., Klotz, S. and Guillon, J. 2003. Instability conditions of marlyhillslopes: towards landsliding of gullying? The case of the Barcelonnette Basin, South East France.Engineering Geology, 70, 109-103.

Mauritsch, H.J., Seiberl, W., Arndt, R., Römer, A., Schneiderbauer, K. and G.P. Sendlhofer 2000. Geophysical investigations of large landslides in the Carnic Region of southner Austria.Engineering Geology, 56, 373-388.

Nolet, G. 1985. Solving or resolving inadequate and noisy tomographic systems. Joumal of Computational Physics, 61, 463-482.

Nolet, G. 1987. Seismic wave propagation and seismic tomography. In: Nolet, G. (Ed.), Seismic Tomography, Reidel, Dordrecht, 1-23.

Paige, C. and Saunders, M. 1982. LSQR: An algorithm for sparse linear equations and sparse least squares. ACM Transaction on Mathematical Software, 8, 43-71.

Palmer, D. and Burke-Kenneth, B.S. 1980.The generalized reciprocal method of seismic refraction interpretation.Society of Exploration Geophysicists.Tulsa, 104 p.

Podvin, P. andLecomte, I. 1991. Finite difference computation of traveltimes in very contrasted velocity model: a massively parallel approach and its associated tools. Geophysical Journal International, 105, 271-284.

Popovici, M. andSethian, J. 1998.Three dimensional traveltimes using the fast marching method. In: Hassanzadeh, S. (Ed) : Proceedings SPIE 3453, Mathematical Methods in Geophysical Imaging V, $82 \mathrm{p}$

Pratt, R.G. 1999. Seismic waveform inversion in the frequency domain. Part 1: Theory and verification in a physic scale model. Geophysics, 64, 888-901.

Romdhane, A., Grandjean, G., Brossier, RM, Réjiba, F., Operto, S. andVirieux, J. 2011.Shallowstructure characterization by 2D elastic full-waveform inversion.Geophysics, 76, 81-93.

Schmutz, M., Albouy, Y., Guérin, R., Maquaire, O., Vassal, J., Schott, J.-J.andDescloîtres, M. 2000. Joint electrical and time domain electromagnetism (TDEM) data inversion applied to the SuperSauze earthflow (France). Surveys in Geophysics, 21, 371-390. 
642 Schön, J.H. 1976. The physical properties of rocks: fundamentals and principles of petrophysics.

643 Pergamon, New York, 601p.

644 Schrott, L. and Sass, O. 2008 Application of field geophysics in geomorphology: Advances and 645 limitations exemplified by case studies. Geomorphology, 93, 55-73.

646 Sirgue, L. and Pratt, R.G. 2004. Efficient waveform inversion and imaging: A strategy for selecting temporal frequencies. Geophysics, 69, 231-248.

648 Spetzler, J. andSnieder, R. 2004. The Fresnel volume and transmitted waves.Geophysics, 69, 653-663.

649 Spetzler, J., Xue, Z., Saito, H. andNishizawa, O. 2008. Case story: Timelapse seismic crosswell 650 monitoring of $\mathrm{CO} 2$ injected in an onshore sandstone aquifer. Geophysical Journal International, $651 \quad 172,214-225$

652 Sun, J., Sun, Z. and Han, F. 2011. A finite difference scheme for solving the eikonal equation including surface topography.Geophysics 76, T53.

Tarantola, A. 1987.Inverse problem theory.Methods for data fitting and model parameters estimation.Society of Industrial and Applied Mathematics, Philadelphia, 342p.

Trampert, J. andLévèque J.-J. 1990. Simultaneous iterative reconstruction technique: Physical interpretation based on the generalized Least Squares solution. Journal of Geophysical Research, 95, 553-559.

Travelletti, J. and Malet, J.-P. 2012. Characterization of the 3D geometry of flow-like landslides: A methodology based on the integration of heterogeneous multi-source data. Engineering Geology, $128,30-48$.

van Asch, Th.W.J., Malet, J.-P. and van Beek, L.H.P. 2006. Influence of landslide geometry and kinematic information to describe the liquefaction of landslides: Some theoretical considerations. Engineering Geology, 88, 59-69.

van Dam, R.L. 2010. Landform characterization using geophysics-Recent advances, applications, and emerging tools. Geomorphology.In press.

van der Sluis, A. and van der Vorst, H.A. 1987. Numerical solutions of large, sparse linear systems arising from tomographic problems. In: Nolet, G. (Ed): Seismic Tomography with Applications in Global Seismology and Exploration Geophysics, Reidel, Dordrecht, 53-87. 
Vasco, D.W., Peterson, J.E. andMajer, E.L. 1995. Beyond ray tomography: Wavepaths and Fresnel volumes.Geophysics, 60, 1790-1804.

Vidale, J. 1988. Finite-difference calculation of travel time.Bulletin Seismological Society of America, 78, 2062-2076.

Virieux, J. andOperto, S. 2009. An overview of full waveform inversion in exploration geophysics.Geophysics, 74(6), WCC1-WCC26.

Watanabe, T. andSassa, K. 1996. Seismic attenuation Tomography and its application to rock mass evaluation. International Journal of Rock Mechanics and Mining Sciences, 33(5), 467-477.

Watanabe, T., Matsuoka, T. andAshida Y. 1999.Seismic traveltime tomography using Fresnel volume approach.69th Proceedings, Society Exploration Geophysics, Houston, USA, SPRO12.5.

Yomogida, K. 1992. Fresnel zone inversion for lateral heterogeneities in the Earth.Pure and Applied Geophysics, 138, 391-406.

Zelt, C.A. and Barton, P.J. 1998. Three-dimensional seismic refraction tomography: A comparison of two methods applied to data from the Faeroe Basin. Journal of Geophysical Research, 103(B4), 7187-7210.

Zhao, H. 2005. A fast sweeping method for eikonal equations.Mathematics of Computation, 74, 603627.

Zhao, L., and Jordan, T.H. 2006. Structural sensitivities of finite-frequency seismic waves: A fullwave approach. Geophysical Journal International, 165, 981-990.

\section{Figure Captions}



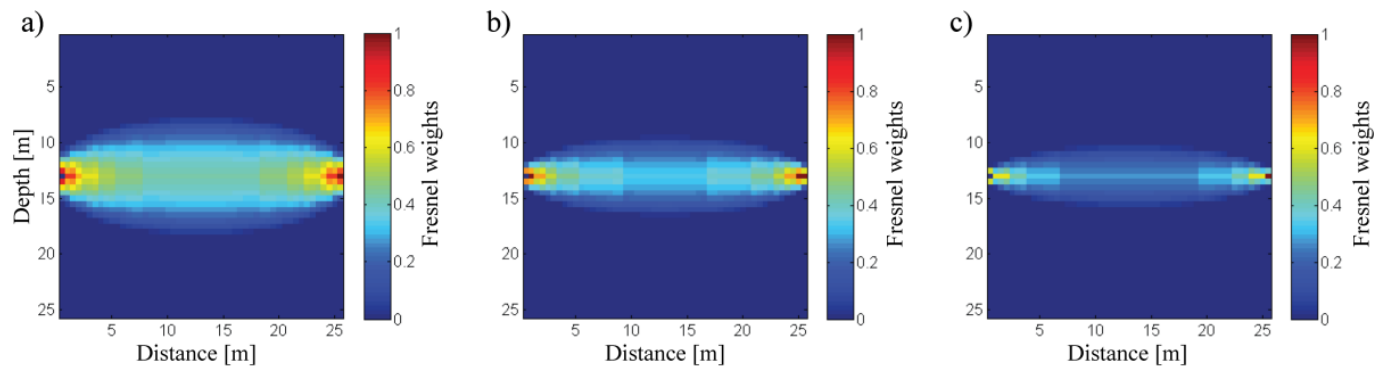

695

696

697

Figure 1: Fresnel weights (e.g. distance versus depth) computed for a medium characterized by a 698 constant velocity of $500 \mathrm{~m} . \mathrm{s}-1$ and for three frequencies: a) $100 \mathrm{~Hz}$, b) $200 \mathrm{~Hz}$ and c) $300 \mathrm{~Hz}$. The 699 source is located at $\mathrm{x}=0 \mathrm{~m}$ and the receptor at $\mathrm{x}=25 \mathrm{~m}$, both at $12.5 \mathrm{~m}$ of depth. 

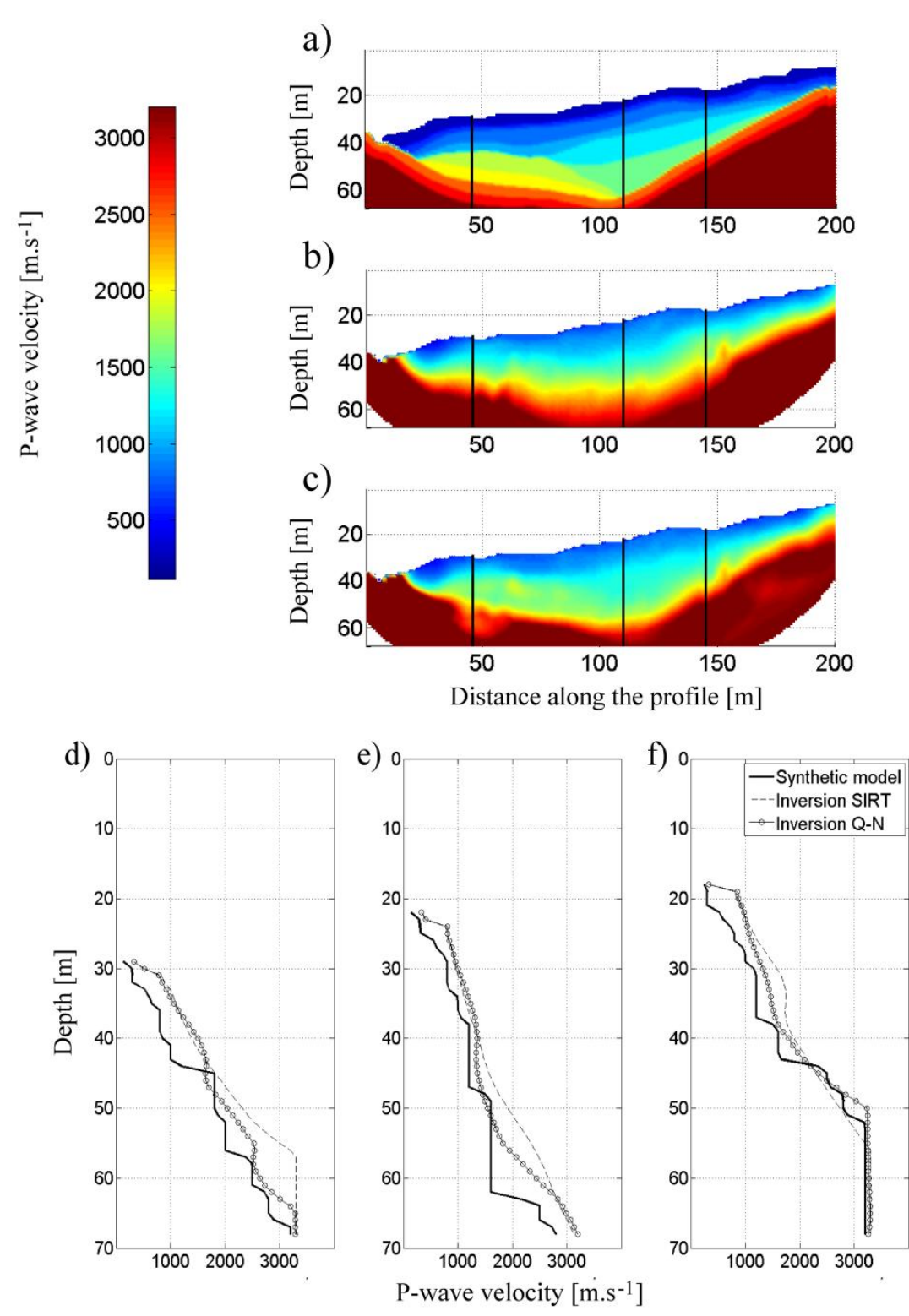

Figure 2: Algorithm validation on a synthetic dataset: a) Synthetic initial model, b) Final velocity model inverted with the SIRT algorithm, c) Final velocity model inverted with the Q-N algorithm.

705 Vertical cross-sections extracted from the three models at a distance of $46 \mathrm{~m} \mathrm{~d}), 110 \mathrm{~m} \mathrm{e}$ ) and $145 \mathrm{~m}$ f). 


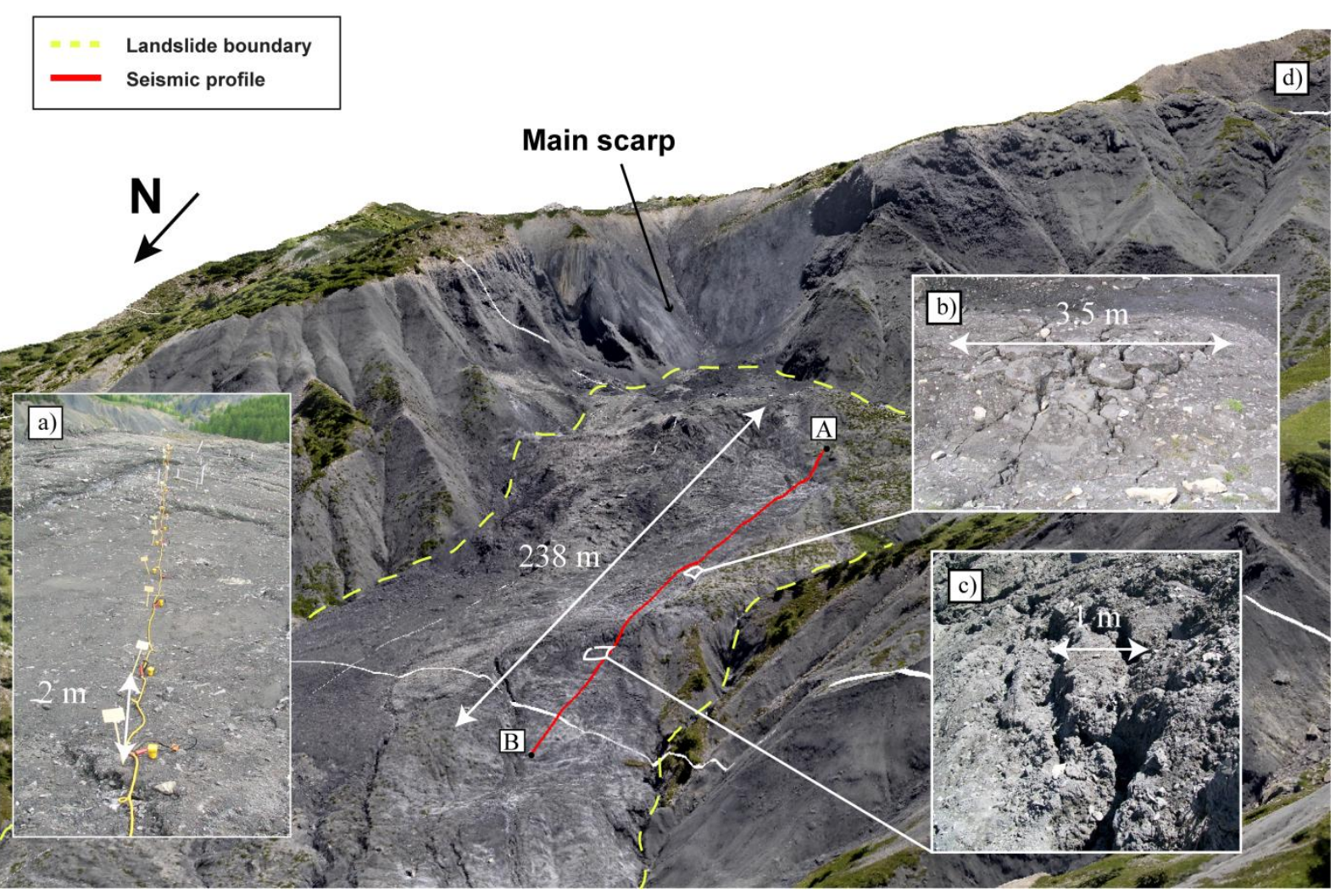

Figure 3: Location of the investigated area within the Super-Sauze landslide. The seismic profile

711 (red) is represented on an orthophotograph overlaid on a digital elevation model of the landslide. The

712 main scarp and the landslide limit. Picture a) shows the seismic device on the field. Picture b) and c)

713 represent the observed fissure state of the soil along the profile.

a)

$\begin{array}{llllllllll}\text { Offset (m) } & 8 & 18 & 28 & 38 & 48 & 58 & 68 & 78 & 88\end{array}$

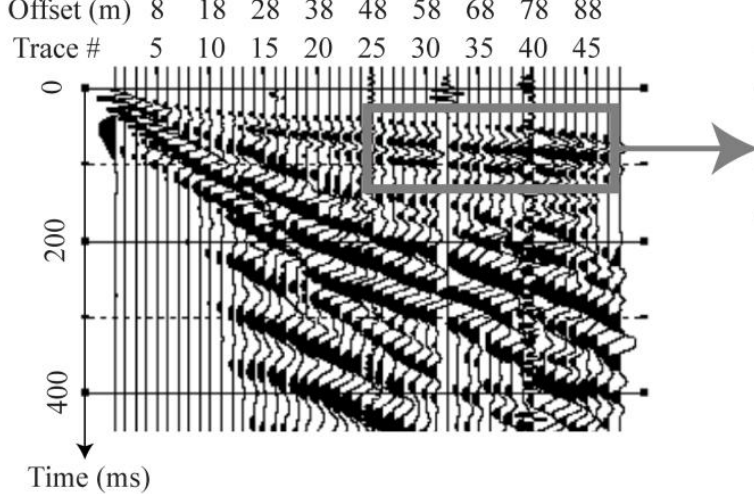

b)

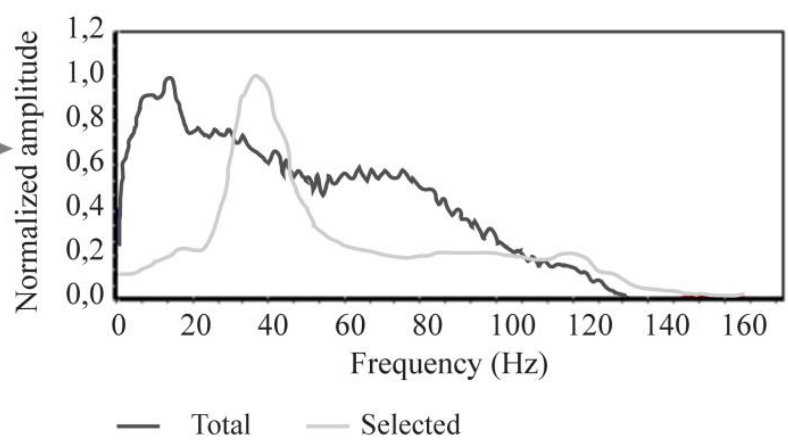

Figure 4: Data quality: a) Seismic shot\# 13. b) Source amplitude spectrum of the total seismic shot

716 (blue) and source amplitude spectrum of the P-wave of the selected area (red). 


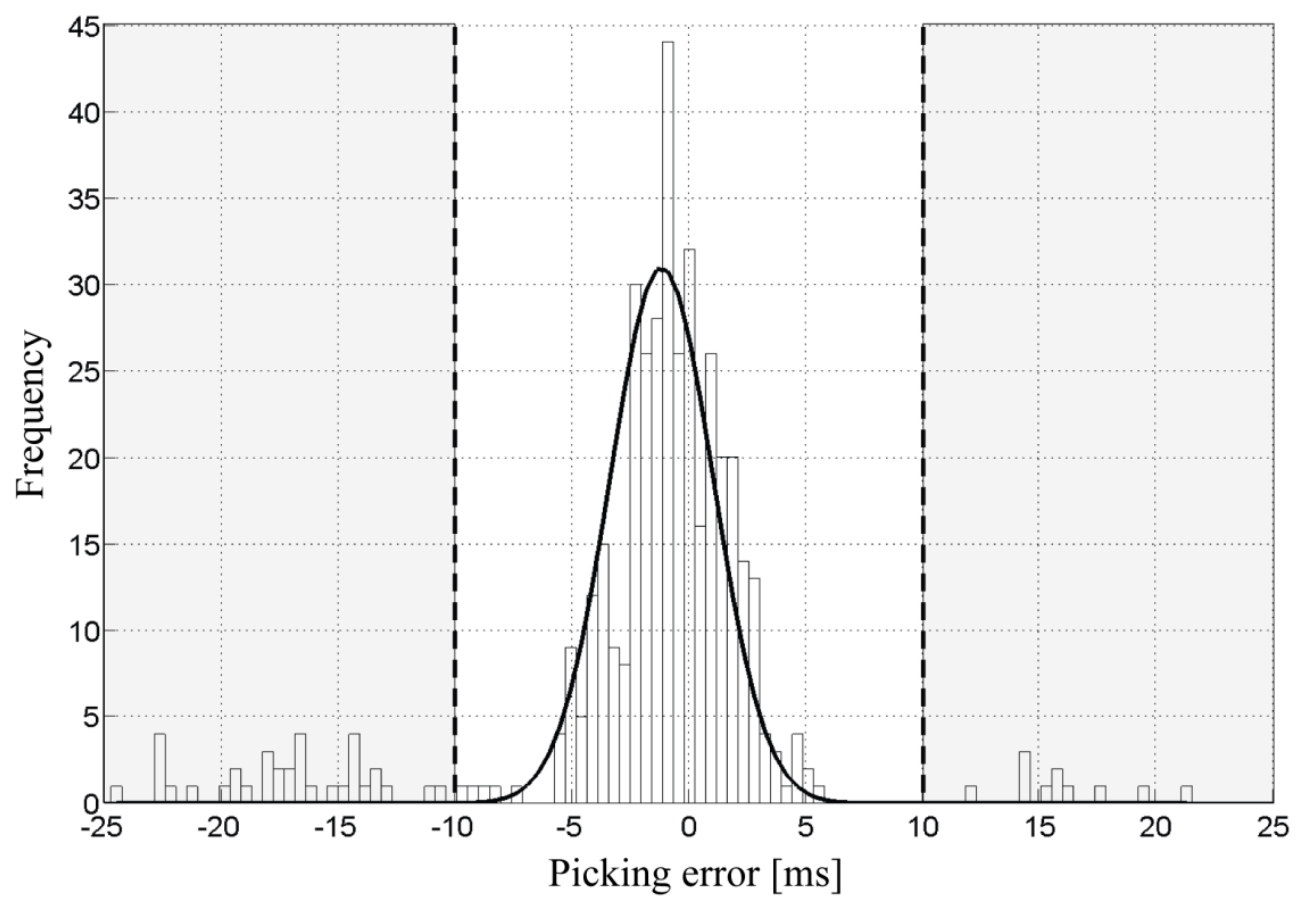

717

718

719

Figure 5: Picking quality: Frequency distribution of differential traveltime errors (e.g. due to reciprocal differences). The standard deviation has a value of $2.2047 \mathrm{~ms}$ for 427 tested reciprocal traveltimes. The grey color indicates the data rejected in the inversion process. 

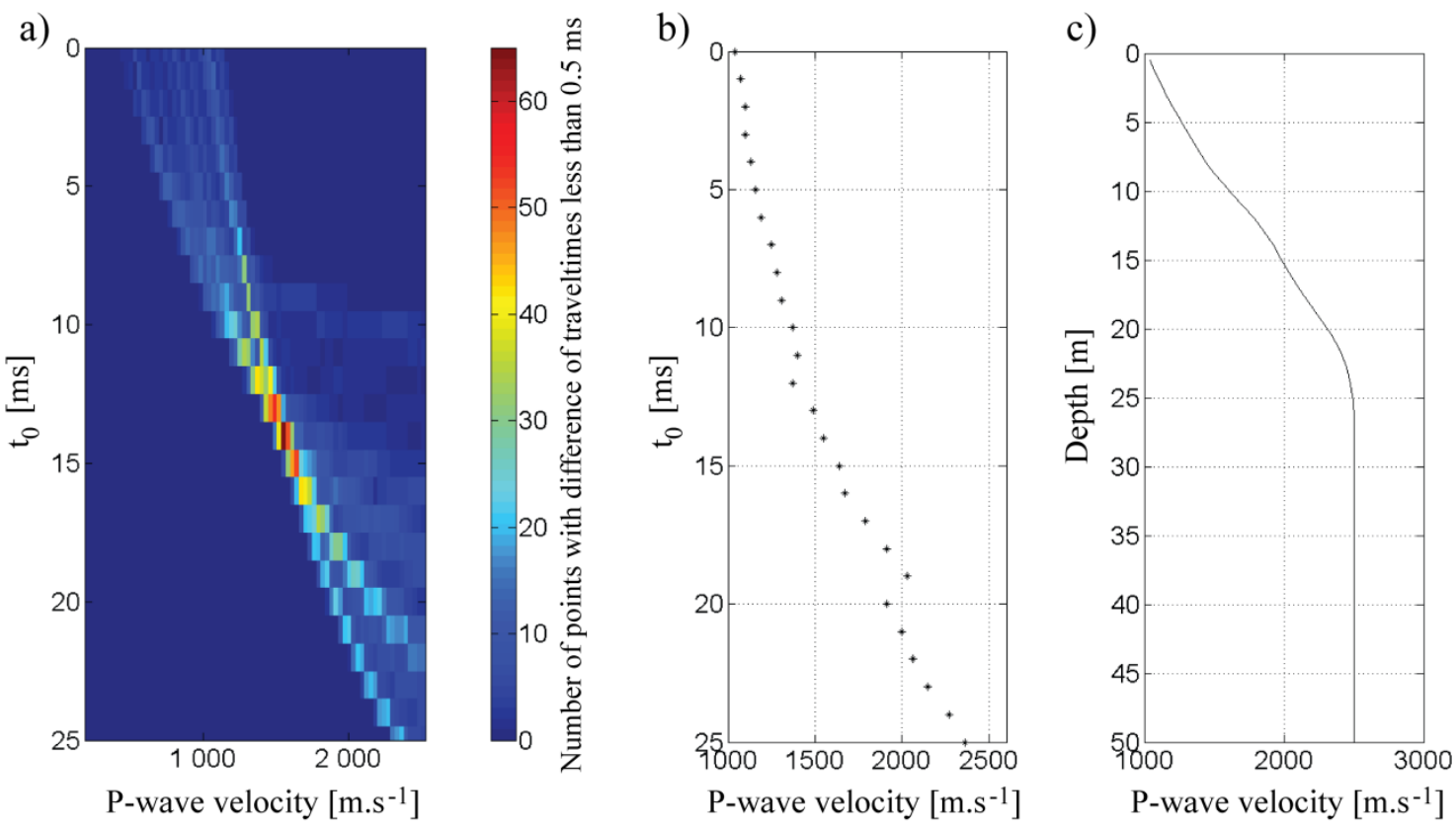

Figure 6: Example of vertical P-wave velocity profile for the seismic shot \#4: a) Slant-stack profile for each t0, c) Vertical velocity profile inverted for the shot \#4.

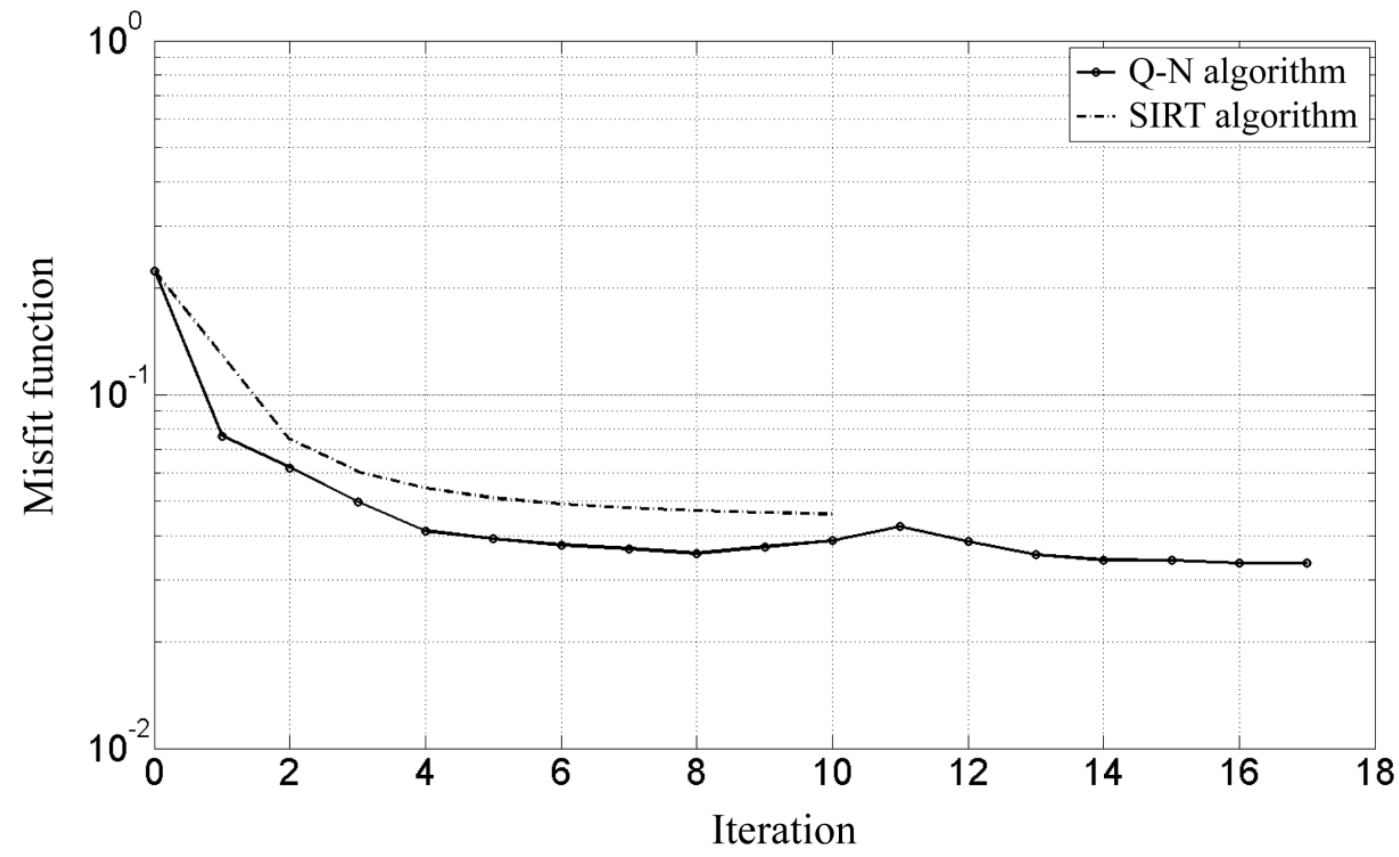


Figure 7: Misfit function values for the Q-N and SIRT algorithms.

732 

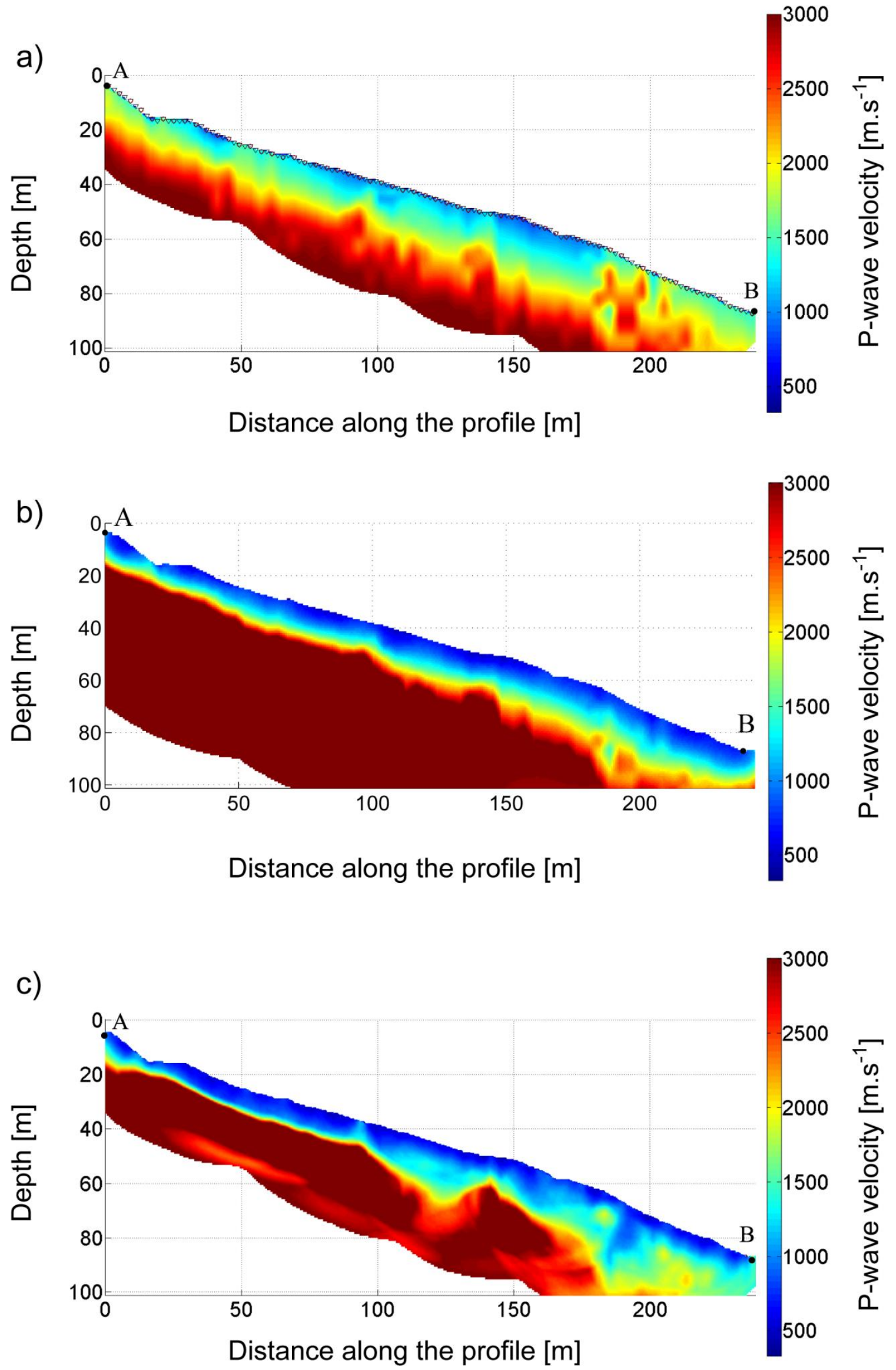
Figure 8: Inversion results of the real dataset acquired on the Super-Sauze landslide: a) initial 736 velocity model, b) inverted model with the SIRT algorithm of Grandjean and Sage (2004), and c) 737 inverted model with the Q-N algorithm.

738
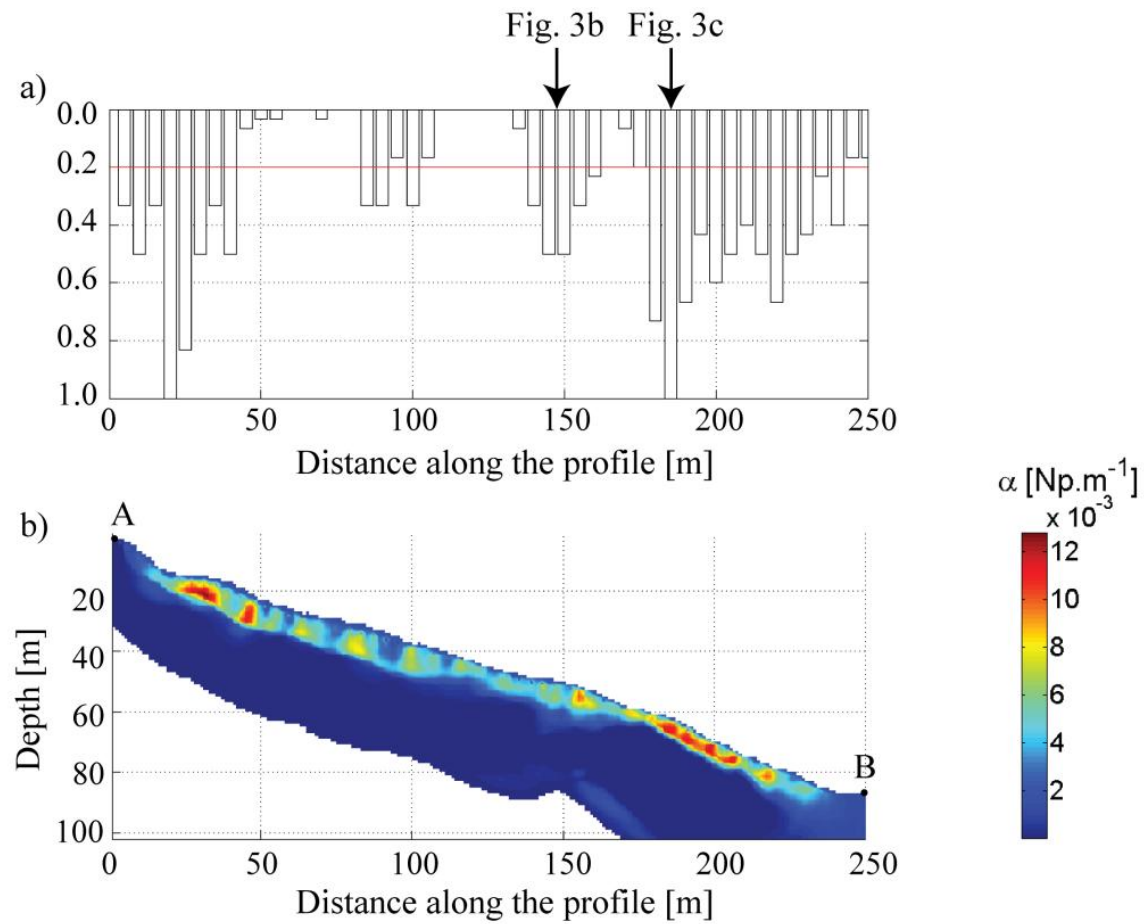

739

Figure 9: Seismic wave attenuation tomography: a) Surface Craking Index (SCI) and b)

742 attenuation section inverted from the Super-Sauze data. 


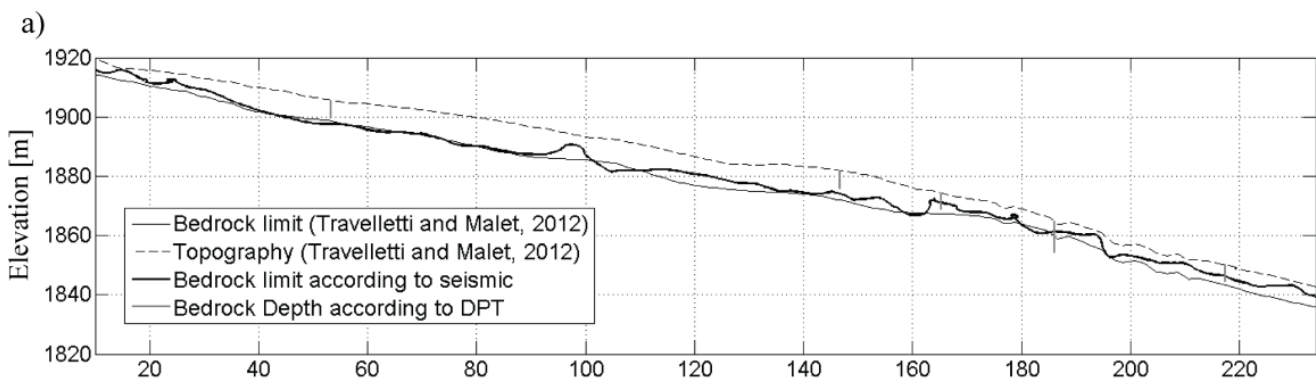

b)

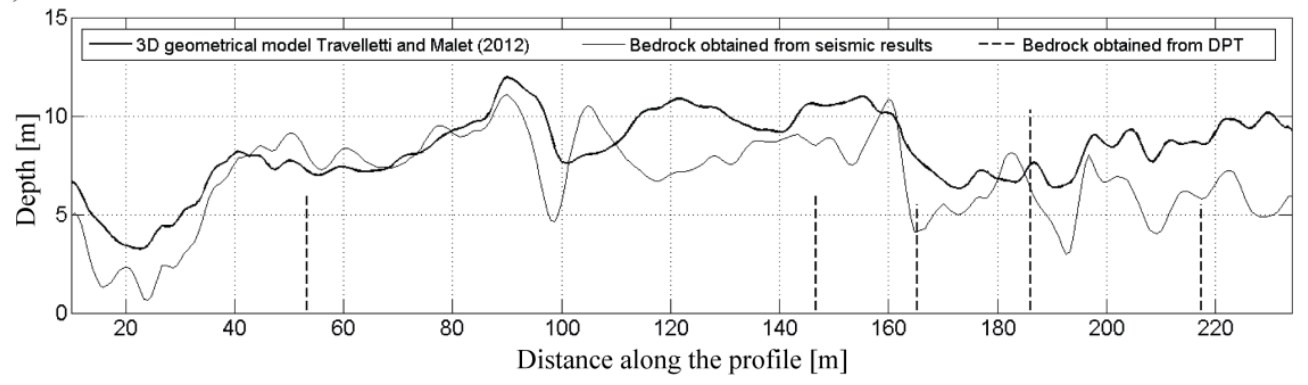

Figure 10: Comparison of the bedrock geometry interpreted with the Q-N algorithm and with a

747 geological modeler by integration of multi-source information at coarser spatial resolution (Travelletti and Malet, 2012) in terms of bedrock depth a) and layer thickness b). 


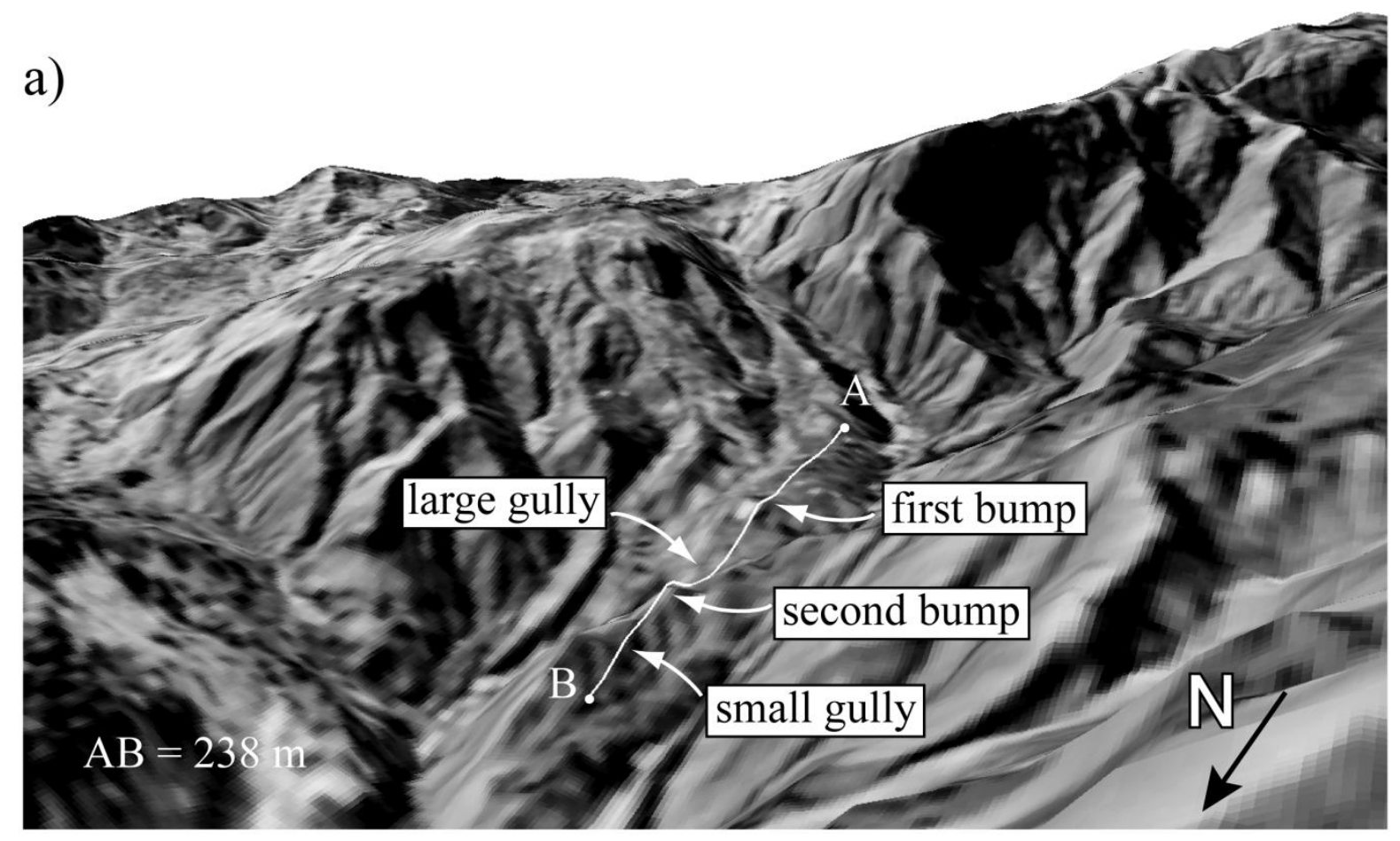

b)

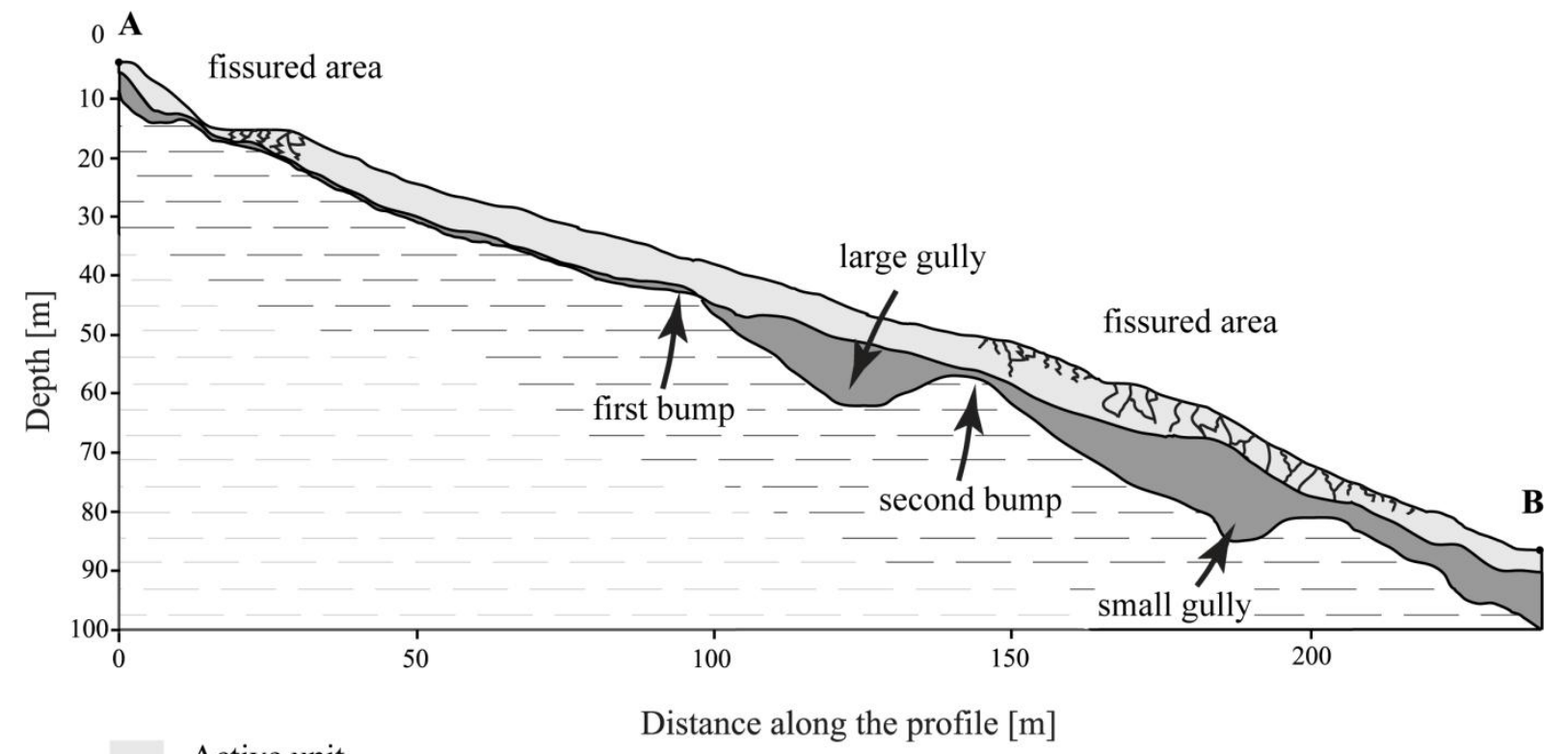

Active unit

Dead body

- In-situ black marls (bedrock)

Figure 11: a) Pre-event topography before the landslide and location of the seismic profile, b)

753 Interpreted geological cross-section in 3 layers: the active unit corresponds to the moving landslide 
754 layer, the dead body is a compacted and quasi-impermeable layer showing low displacements and the 755 bedrock constituted of in-situ black marls. 